\title{
Effect of Zn dopant on Properties of Li ferrite Synthesized by Solution Combustion Method
}

\author{
Anu \\ Department of Chemistry, BUC College, Batala (Gurdaspur), Punjab, India
}

\begin{abstract}
Herein, Urea assisted solution combustion method has been used for the preparation of stoichiometrically pure and $\mathrm{Zn}$ doped $\mathrm{Li}$ ferrites. Urea acts as a capping agent and helps in the formation of nanostructures. Solution combustion method helps easier formation of ferrites in a single step, at relatively lower temperature and in shorter time than the reported methods. Powder X-ray diffraction (XRD) studies with diffractometer indicate high purity, single phase spinel ferrites formation. Magnetic studies by vibratory sample magnetometer (VSM) reveal an increase in the magnitude of saturation magnetization with increasing $\mathrm{Zn}$ content up to $\mathrm{x}=0.3$. The $\mathrm{Zn}$ doped Li ferrite formed possess high dc-resistivity values which make them suitable for high-frequency applications. Apart from the academic interest involved, these investigations are of technological importance in the view of the fact that their end products (ferrites) play a key role as electro-magnetic materials in the modern industry.
\end{abstract}

Keywords: Solution combustion method, powder X-ray diffraction, Powder X-ray diffraction, saturation magnetization, dc-resistivity.

\section{INTRODUCTION}

Alkali metal ferrites find extensive use in microwave components due to their attractive electrical and magnetic properties [1-11]. Ferrites have been reported as better electromagnetic materials than pure metals because of their low cost, high resistivity and ease of preparation. The properties of the ferrite materials, which decide the application areas, are generally governed by the chemical compositions along with the procedures followed for their preparation. Therefore, the molecular engineering of ferrite composition and employment of appropriate process parameters play a significant role in tailoring the material properties for a specific need. The properties of the ferrites can be modified by substituting the optimum amount of metal ions as dopant in the basic compositional formulae. It is, therefore, desirable to investigate and understand the dependence of composition on magnetic/electric behavior of these ferrites.

Ferrite nanoparticles show unusual magnetic properties such as single domain behavior and superparamagnetism which are not observed in bulk material $[12,13]$. Also, the resistivity of the ferrites at room temperature can vary from $10^{-2}$ to $10^{11} \mathrm{ohm}-\mathrm{cm}$ [14-16]. The change in the resistivity is brought about by substitution of some appropriate metal ion in the metal site. To obtained sample with high resistivity, it is necessary to ensure that there are no ferrous ions in the stoichiometric ferrite. Therefore, chemical aspect has become the most important factor in the design and preparation of ferrite materials. Solution combustion method has been found to be the most suitable technique for the synthesis of a particular mixed ferrite composition. The properties of the final product (particle size, surface area and porosity) depend on the way the combustion is conducted. The departure of gases favours the desegregation of the products (increasing the porosity) and heat dissipation (inhibiting the sintering of the products). The exothermicity of the combustion is controlled by the nature of the fuel used and the ratio of oxidizer to fuel. The properties are also considered important for the selection of material for device application. In this paper, a detailed investigation has been made on synthesis, characterization and electro-magnetic studies of pure and $\mathrm{Zn}$ doped Li ferrites [17] using solution combustion method.

\section{EXPERIMENTAL}

The most extensively used technique for the bulk preparation of ferrites is the conventional ceramic method. However, this method has certain limitations viz. milling of the starting materials which incorporates lattice defects and strains in the ferrite obtained which, in turn, affect its permanent magnetic properties. In solution combustion method, there is a direct conversion from the molecular mixture of the precursor solution to the final oxide (ferrite) product, avoiding formation of intermediate phases that require inter-diffusion for complete reaction. This technique has, therefore, been undertaken to prepare powder ferrites with varying composition in pure phase. The given equation shows the formation of ferrite from the reactant at $600{ }^{\circ} \mathrm{C}$.

$$
\mathrm{LiNO}_{3(\mathrm{aq})}+\mathrm{Fe}\left(\mathrm{NO}_{3}\right)_{3(\mathrm{aq})}+2 \mathrm{NH}_{2}-\mathrm{CO}-\mathrm{NH}_{2(\mathrm{aq})} \underset{\mathrm{urea}, 600 \mathrm{C}}{\longrightarrow} \mathrm{MFeO}_{2}+4 \mathrm{CO}_{2}(\mathrm{~g})+2 \mathrm{~N}_{2}(\mathrm{~g})+15 \mathrm{H}_{2} \mathrm{O}(\mathrm{g})
$$




\section{RESULTS AND DISCUSSION}

\subsection{XRD studies}

Figure 1 shows the X-ray diffraction patterns for different compositions of $\mathrm{Zn}$ doped Li ferrites. The diffraction peaks reveal the existence of single phase cubic spinel ferrites and are comparable to those reported for respective lithium ferrites. Figure 2 shows the variation of lattice constant (Table 1) as a function of ' $x$ ' which is attributed to the substitution of larger $\mathrm{Zn}^{2+}$ cation $(0.083 \mathrm{~nm})$ for smaller $\mathrm{Fe}^{3+}$ cation $(0.067 \mathrm{~nm})$. Lithium ferrite being inverse spinel, have all the $\mathrm{Li}^{+}$ions in octahedral position along with half of the $\mathrm{Fe}^{3+}$ ions and remaining $\mathrm{Fe}^{3+}$ ions occupy tetrahedral site. On addition of $\mathrm{Zn}^{2+}$ ions which have strong affinity for tetrahedral site, only $\mathrm{Fe}^{3+}$ ions present at tetrahedral site get replaced resulting in an increase in lattice parameter. The theoretical / X-ray density $\left(\mathrm{d}_{\mathrm{XRD}}\right)$ and experimental densities (Figure 3) show a regular decrease with increasing ' $x$ ' value due to a decrease in molecular weight of the ferrite compositions. The average particle sizeof the ferrite product calculated from the XRD pattern comes out to be 15-20 $\mathrm{nm}$. The size and shape of $\mathrm{Zn}$ doed Li ferrite particles synthesized by the solution combustion route were also analyzed by transmission electron micrographs (TEM). An average particle size of 18-22 nm has been estimated for the nanocrystalline powders as shown in Figure 4. The smaller particle size may be attributed to the combustion synthesis involving molecular level heating without thermal gradient and requiring much smaller time than the conventional sintering ceramic technique.

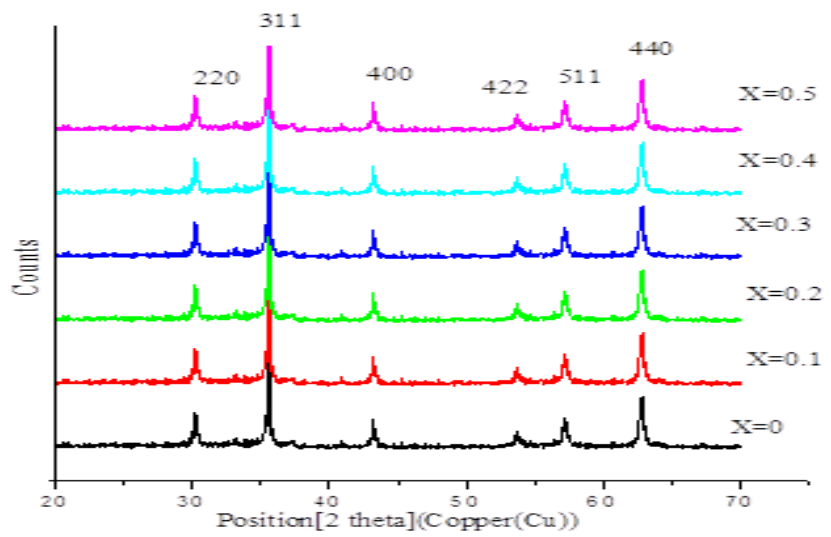

Fig.1. X-ray powder diffraction patterns for $\mathrm{Zn}$ doped lithium ferrite( $\mathrm{x}=0$ to 0.5 )

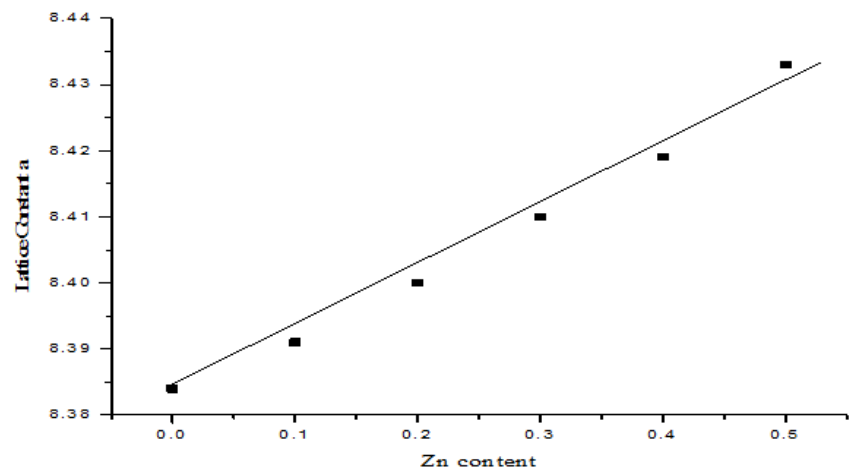

Fig.2. Variation of Lattice constant 'a' with $\mathrm{Zn}$ content.

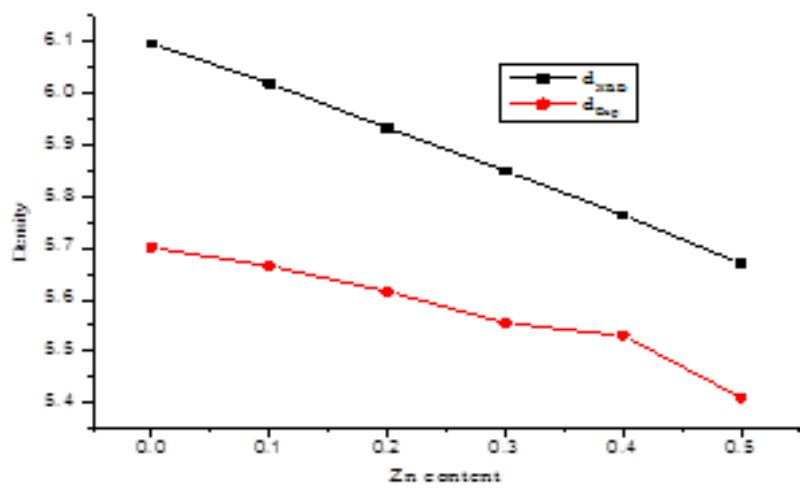

Fig.3. Variation of theoretical density $\left(\mathrm{d}_{\mathrm{XRD}}\right)$ and experimental density $\left(\mathrm{d}_{\mathrm{Exp}}\right)$ with Zn content $(\mathrm{x})$. 


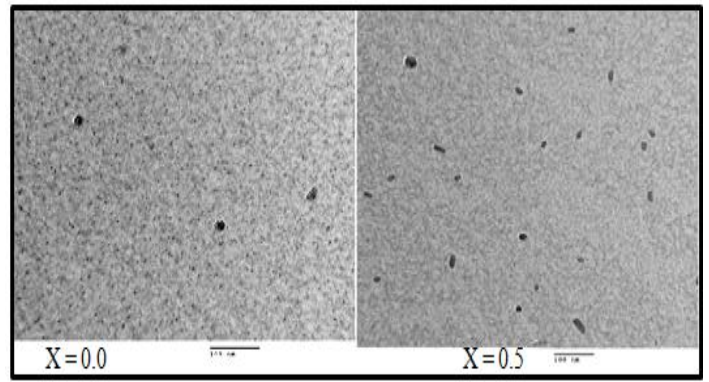

Fig.4. TEM micrograph for $\mathrm{Zn}$ doped Li ferrites with $\mathrm{x}=0.1$ and $\mathrm{x}=0.5$

\subsection{Magnetic studies}

Magnetic measurements reveal that all the samples show typical ferromagnetic hysteresis loop, for nanosized magnetic materials. Figures 5 show the variations of saturation magnetization and Curie temperature as a function of $\mathrm{Zn}$ content.

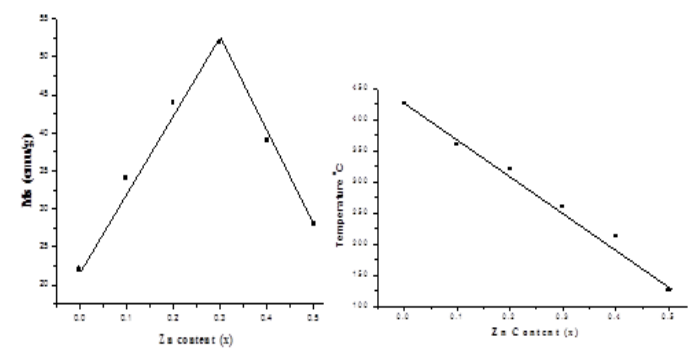

Fig.5. Variation of saturation magnetization and Curie temperaturewith increasing value of ' $\mathrm{x}$ '

\subsection{Electrical studies}

The electrical property in $\mathrm{Zn}$ doped Li ferrites has been attributed to electron hopping between the two valence states of iron, $\mathrm{Fe}^{2+} \leftrightarrow \mathrm{Fe}^{3+}$, on octahedral sites. The $\mathrm{Fe}^{2+}$ ion concentration is a characteristic property of a given ferrite material and depends upon several factors such as sintering time, temperature and atmosphere, annealing time, etc., including the particle structure. The variation of room-temperature dc-resistivity as a function of composition is presented in Table 1. It shows a regular increase with Zn content as shown in Figure 6 and can be explained on the basis of Verwey mechanism of electron hopping between two valance states distributed randomly on equivalent lattice sites [18-23].

The temperature dependence of dc-resistivity was also studied in the temperature range 308-398 $\mathrm{K}$ as displayed in the Figure 7 that shows an almost linear decrease in resistivity with temperature suggesting semiconductor behavior of the ferrite materials.

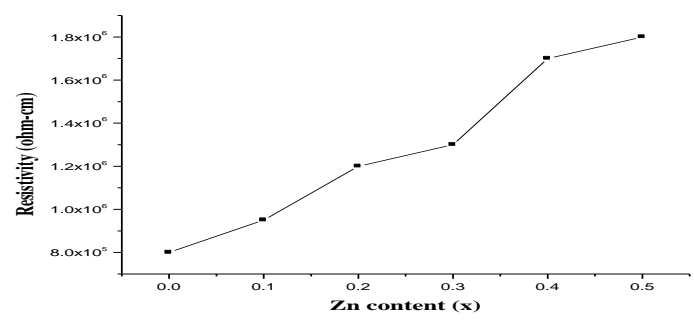

Fig. 6. Variation of de resistivity with $\mathrm{Zn}$ content

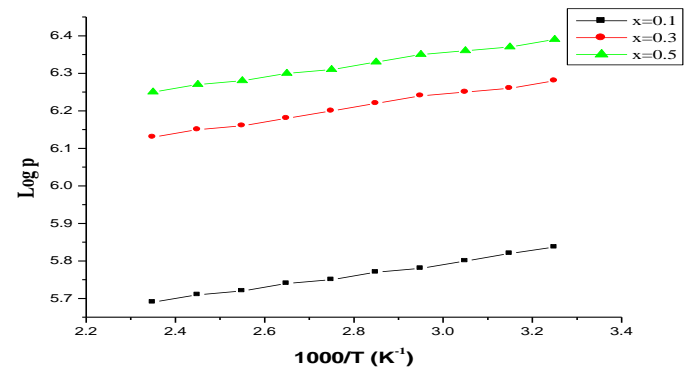

Fig.7. Temperature dependence of dc- resistivity for composition $\mathrm{x}=0.1,0.3,0.5$ 
Dielectric properties for different ferrite samples were studied in the frequency range $10^{2}-10^{7} \mathrm{~Hz}$, (Figure 8 ). The frequency dependence of the dielectric constant $\left(\varepsilon^{\prime}\right)$ shows a continuous decrease with increase in frequency with pronounced dispersion at lower frequency and it remains almost independent of applied external field at high frequency domain. The existence of dielectric dispersion can be explained on the basis of Koop's two-layer model and MaxwellWagner polarization theory.

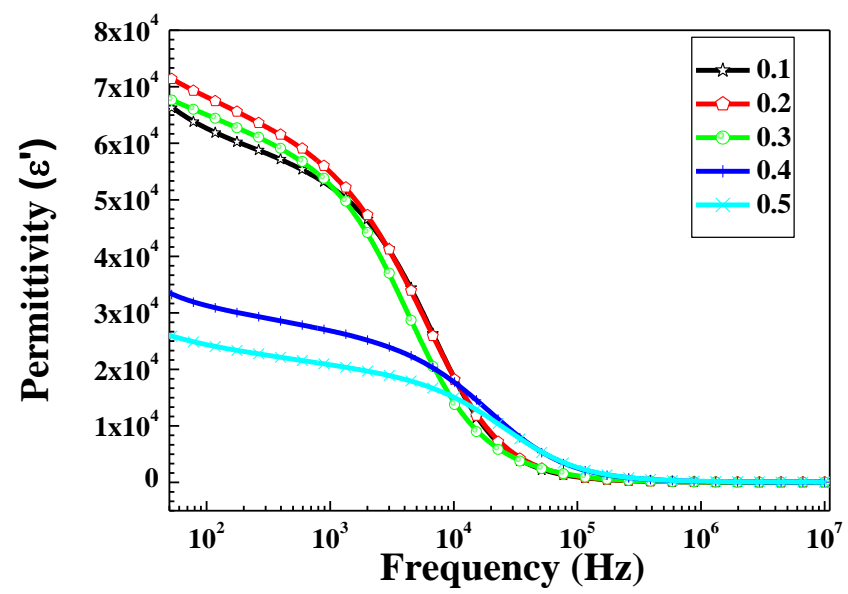

Fig. 8. Variation of Dielectric constant for different compositions with frequency.

Figure 9 shows an initial increase in the value of tangent loss $(\delta)$ to attain a maxima followed by a regular decrease with frequency. It can be noted that the height of the peak increases with $\mathrm{Zn}^{2+}$ ions substitution at $\mathrm{x}=0.1$, and then it shows a subsequent decrease with increase of $\mathrm{Zn}^{2+}$ ion concentration. The decrease of the height of the peak of tan $\delta$ may be attributed to the substitution of diamagnetic $\mathrm{Zn}^{2+}$ ions in place of $\mathrm{Fe}^{3+}$ ions that limits the degree of conductivity by blocking hopping conduction mechanism, thus, resulting in an increase of resistivity.

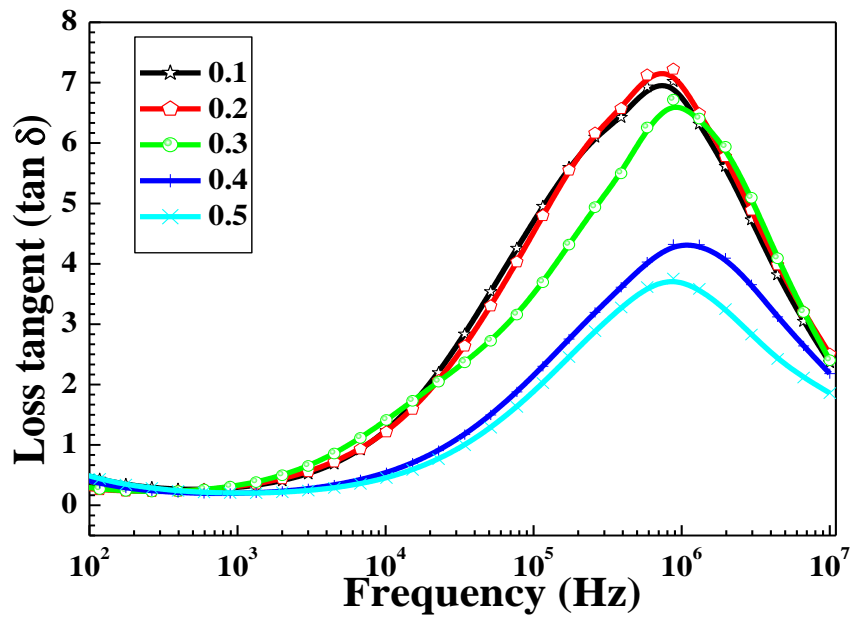

Fig.9. Variation of Tangent loss $(\delta)$ for different compositions with frequency.

\section{CONCLUSIONS}

Urea assisted solution combustion method has been used for the preparation of stoichiometrically pure ferrites at lower temperature and in shorter time than the conventional ceramic method. X-ray powder diffraction studies reveal the formation of single phase spinel ferrites, which ensures the high purity of materials. The lattice parameter ' $a$ ' has been found to increase with increasing $\mathrm{Zn}$ content $(\mathrm{x})$ which is attributed to the larger cationic radii of substituent $\mathrm{Zn}^{2+}$ ions than $\mathrm{Fe}^{3+}$ ions being replaced.An increase in the magnitude of saturation magnetization with increasing $\mathrm{Zn}$ content up to $x=0.3$ has been explained on the basis of Neel's two sublattices model. The high dc-resistivity values obtained for the solution combustion route processed $\mathrm{Zn}$ doped Li ferrites make them suitable for high-frequency applications.Apart from the academic interest involved, these investigations are of technological importance in the view of the fact that their end products (ferrites) play a key role as magnetic/engineering materials in the modern industry. 


\section{UGC Approved Journal}

Vol. 4, Issue 7, July 2017

Table1. Variation of Saturation magnetization, Curie's temperature and dc- resistivity with different composition ' $\mathrm{x}$ '

\begin{tabular}{|l|l|l|l|}
\hline Composition $(\mathrm{X})$ & $\begin{array}{l}\text { Saturation Magnetization } \\
\text { Ms }(\mathrm{emu} / \mathrm{g})\end{array}$ & Curie's temperature $\left({ }^{0} \mathrm{C}\right)$ & Resistivity $(\mathrm{Ohm}-\mathrm{cm})$ \\
\hline 0 & 22 & 425 & $8.02 \times 10^{5}$ \\
\hline 0.1 & 34 & 360 & $9.5 \times 10^{5}$ \\
\hline 0.2 & 44 & 320 & $1.23 \times 10^{6}$ \\
\hline 0.3 & 52 & 260 & $1.35 \times 10^{6}$ \\
\hline 0.4 & 39 & 210 & $1.67 \times 10^{6}$ \\
\hline 0.5 & 28 & 126 & $1.80 \times 10^{6}$ \\
\hline
\end{tabular}

\section{ACKNOWLEDGEMENT}

Author is highly thankful to Dr. B.S. Randhawa, Professor, GNDU, Amritsar, for dielectric analysis of the samples.

\section{REFERENCES}

[1] M.A. Dar, K.M. Batoo, V. Verma, W.A. Siddiqui, R.K. Kotnala, J. Alloys Comp. 493(2010) 553-560.

[2] M. Srivastava, S. Chaubey, A.K. Ojha, Mater. Chem. Phys. 118 (2009) 174-180.

[3] V. Verma, S.P. Gairola, M.C. Mathpal, S. Annapoorni, R.K. Kotnala, J. AlloysComp. 481 (2009) $872-876$.

[4] D.A. Domínguez, I.Á. Serrano, M.L. López, M.L. Veiga, C. Pico, F. Mompeán, M.G.Hernández, G.J. Cuello, J. Alloys Comp. 577 (2013) 269277.

[5] F. Grasset, N. Labhsetwar, D. Li, D.C. Park, N. Saito, H. Haneda, O. Cador, T.Roisnel, S. Mornet, E. Duguet, J. Portier, J. Etourneau, Langmuir 18 (2002)8209-8216.

[6] M.A. Ahmed, N. Okasha, S.I. El-Dek, Nanotech. 19 (2008) 065603.

[7] Soibam, S. Phanjoubam, C. Prakash, J. Alloys Comp. 475 (2009) 328-331.

[8] M.P. Reddy, W Madhuri, N.R. Reddy, K.V.S. Kumar, V.R.K. Murthy, R.R. Reddy,Phys. Scr. 81 (2010). 055801-055801.

[9] T. Namgyal, J. Singh, K. Chandra, S. Bansal, S. Singhal, J. Mol. Struct. 1019 (2012)103-109.

[10] S. Sutradhar, S. Pati, S. Acharya, S. Das, D. Das, P.K. Chakrabarti, J. Mag. Mag.Mater. 324 (2012) 1317-1325.

[11] Y.P. Fu, S.H. Hu, Ceram. Int. 36 (2010) 1311-1317.

[12] R.P. Patil, P.P. Hankare, K.M. Garadkar, R. Sasikala, J. Alloys Comp. 523 (2012)66-71.

[13] M.A. Iqbal, M. Islam, M.N. Ashiq, I. Ali, A. Iftikhar, H. M. Khan, J. Alloys Comp.579 (2013) 181-186.

[14] A.M. Samy, A.A. Sattar, I.H. Afify, J. Alloys Comp. 505 (2010) 297-301.

[15] M.F.A. Hilli, S. Li, K.S. Kassim, J. Mag, Mag. Mater. 324 (2012) 873-879.

[16] A.A. Sattar, W.R. Agami, J. Alloys Comp. 496 (2010) 341-344.

[17] N. Singh, A. Agarwal, S. Sanghi, J. Alloys Comp. 509 (2011) 7543-7548.

[18] H.M. Widatallah, E.A. Moore, A.A. Babo, M.S.A. Barwani, M. Elzain, Mater. Res.Bull. 47 (2012) 3995-4000.

[19] A.K.M.A. Hossain, M.A. Rahman, S.F.U. Farhad, B. Vilquin, H. Tanaka, Phys. BCondens. Matter 406 (2011) $1506-1512$

[20] K.P. Chae, W.H. Kwon, J.G. Lee, J. Mag. Mag. Mater. 324 (2012) 2701-2705

[21] S.T. Assar, H.F. Abosheiasha, J. Mag. Mag. Mater. 324 (2012) 3846-3852.

[22] S.K. Gurav, S.E. Shirsath, R.H. Kadam, D.R. Mane, Powder Technol. 235 (2013)485-492.

[23] W.H. Qi, M.P. Wang, J. Nanopart. Res. 7 (2005) 51-57. 